\title{
Drought resistance of native pioneer species indicates potential suitability for restoration of post-mining areas
}

\author{
N. Winkler ${ }^{1}$, W. Weymann ${ }^{2}$, H. Auge ${ }^{1}$, S. Klotz ${ }^{1}$, P. Finkenbein ${ }^{1}$, and H. Heilmeier ${ }^{2}$ \\ ${ }^{1}$ Department of Community Ecology, UFZ - Helmholtz Centre for Environmental Research, \\ Theodor-Lieser-Str. 4, 06120 Halle (Saale), Germany \\ ${ }^{2}$ Interdisciplinary Ecological Centre, TU Bergakademie Freiberg, Leipziger Str. 29, 09599 Freiberg, Germany
}

Correspondence to: N. Winkler (nicole.winkler@ufz.de)

Received: 31 October 2014 - Accepted: 24 November 2014 - Published: 9 January 2015

\begin{abstract}
In order to test whether invasive exotic species, predominantly used for restoring post-mining areas in north-eastern Vietnam, may be replaced by ecologically superior native pioneer species, we conducted a drought stress experiment in a greenhouse. We hypothesized that juvenile individuals of four native pioneer tree and two native pioneer grass species have a drought resistance comparable to two exotic reference species. Our results confirm this hypothesis: even under drought, native trees had a higher biomass and root : shoot ratio than exotic trees, although their maximum relative elongation rate and biomass were reduced more strongly than for exotic trees with respect to well-watered conditions. Native grasses had a higher root length density and a similar drought-induced reduction of stomatal conductance compared to exotic trees. In spite of a higher biomass reduction, native grasses produced more biomass under drought in absolute terms. Notwithstanding that further investigations of other adverse environmental factors need to be performed, our results indicate with respect to drought resistance that native pioneer species are a potential alternative to exotic species for the ecological restoration of subtropical post-mining areas, which may accelerate secondary succession.
\end{abstract}

1

\section{Introduction}

Open-cast coal mining is associated with the removal of soil and vegetation of vast areas. Especially the current economic growth in Asian countries results in the expansion of mining sites (US Energy Information Administration, 2011). The remaining post-mining areas are devastated areas of waste rock dumps which need to be replanted to reduce erosion risks and to restore viable ecosystems. Beside the deficiency of nutrients, waste rock dumps are often characterized by coarsegrained substrates with a low water storage capacity and high surface run-off on steep slopes. Therefore, in subtropical areas, especially during the dry season, plants may suffer from drought. Consequently, species' drought resistance is highly relevant for the successful restoration of subtropical postmining areas.

Plant species which are used worldwide for large-scale restoration of post-mining areas in the tropics and subtropics are predominantly fast-growing species of the genera Aca- cia, Casuarina, Eucalyptus, and Pinus (Richardson, 1998). Due to their morphological and ecophysiological traits, these species are well adapted to the harsh conditions in mining areas. Acacia species, for example, develop a deep and extensive root network and are able to fix nitrogen (Morris et al., 2011). However, when plant species are used for restoration outside their native range, they might become invasive. Many of them are able to spread from plantations and are highly invasive all over the world. Examples for invasive species are Acacia auriculiformis and Casuarina equisetifolia, which have already become invasive in 4 (Acacia auriculiformis) and 9 (Casuarina equisetifolia) out of 15 global geographical regions, including Asia (Richardson and Rejmánek, 2011). The invasion of exotic species can lead to the degradation of native habitats and species decline (Vitousek et al., 1997), e.g. by inhibiting germination and initial growth of other species through their allelopathic properties (Ekka and Behera, 2011) or by accumulating litter, as reported for Casuarina equisetifolia (Hata et al., 2010). Fur- 
thermore, litter accumulation of the abovementioned species may increase fire hazard in post-mining areas (Saharjo and Watanabe, 2000).

The use of native species instead of or in addition to exotic species may reduce these risks and provide additional ecological and social benefits by restoring native biodiversity (Lamb, 1998). However, native species, especially those of later successional stages, often grow slowly, are less suitable for degraded sites due to low tolerance of adverse habitat conditions, and the knowledge about their ecology and cultivation is often limited (Lamb, 1998).

The use of native pioneer species in revegetation may compensate for the morphological and ecophysiological disadvantages typical for native species of later successional stages. Pioneer species are often the first to establish in disturbed areas because they have low demands on habitat quality, grow fast, and reach fertility early (Goosem and Tucker, 1995). As ecosystem engineers (Jones et al., 1994) these pioneer species create habitats for later successional stage plants, e.g. by providing shelter from the sun and by contributing to soil formation by litter decomposition. Furthermore, they can provide habitat structure and food for animals (Castro et al., 2006; Goosem and Tucker, 1995).

However, so far little is known about tropical and subtropical pioneer species, inter alia, regarding their drought resistance. Although there are some studies on pioneer species regarding drought resistance in their natural environments such as Markesteijn et al. (2011), until now the focus of studies has not been set on pioneer species in post-mining areas. Therefore, since the success of restoration projects using native pioneer species is hardly predictable, well-studied exotic species of the genera Acacia, Casuarina, Eucalyptus, and Pinus are preferably used around the world (Hau and Corlett, 2003; Lamb, 1998).

In order to enhance knowledge on the suitability of native pioneer species for a restoration project in post-mining areas in subtropical north-eastern Vietnam, we studied drought resistance in a greenhouse experiment under controlled conditions. We investigated functional traits associated with drought resistance of four native pioneer tree and two perennial grass species which occur frequently in Vietnamese postmining areas and compared them to two exotic tree species which are currently planted in monoculture on these areas. We used saplings and juvenile grasses of age and size appropriate for planting in ecological restoration programmes. Due to their shallow root system (Condit et al., 1995; Poorter and Hayashida-Oliver, 2000) juvenile plants are particularly vulnerable to drought stress (Engelbrecht et al., 2006; Turner, 1990; Veenendaal et al., 1996). Moreover, the establishment of juvenile plants is the first critical step in the establishment of a stable vegetation cover.

We hypothesized that both saplings of native pioneer trees and juvenile pioneer grasses show similar traits and responses to drought compared to saplings of currently used exotic trees, and that these native species can therefore be used as a suitable alternative for the restoration of postmining areas.

\section{Methods}

\subsection{Study site}

The project area is situated on waste rock dumps of the open-cast hard coal mine Nui Beo, which is part of the Quang Ninh coal basin. The waste rock dumps are characterized by a coarse-grained substrate and steep slopes (Bui and Nguyen, 2007) with angles up to $30-40^{\circ}$. They are located near the UNESCO World Natural Heritage Ha Long Bay in north-eastern Vietnam (lat $20^{\circ} 59^{\prime} \mathrm{N}$, lon $107^{\circ} 08^{\prime} \mathrm{E}$, 50-250 $\mathrm{m}$ a.s.1.).

In contrast to tropical central and southern Vietnam, subtropical north-eastern Vietnam is characterized by dry winters and hot summers (Peel et al. 2007). The dry and cool season lasts from October to March (monthly precipitation: 14.3 to $169.1 \mathrm{~mm}$, average $53.2 \mathrm{~mm}$ ) and the hot and rainy season lasts from April to September (monthly precipitation: 81.0 to $444.5 \mathrm{~mm}$, average $258.5 \mathrm{~mm}$ ). The average temperature is $21^{\circ} \mathrm{C}$, the annual precipitation is $2000 \mathrm{~mm}$, and the average humidity is $82 \%$ (Thu, 2000).

\subsection{Plant species}

In our experiment we used saplings of native and exotic tree species and juvenile plants of native grass species. Based on a previous vegetation survey, we selected out of a species pool of 192 species 6 native pioneer species (four tree species: Commersonia bartramia, Mallotus barbatus, Melia azedarach, and Rhus chinensis; two grass species: Saccharum spontaneum and Thysanolaena maxima) that frequently occur in more-than-10-year-old successional areas of the study site. According to the vegetation survey the four pioneer tree species chosen for analysis occurred on 3 to 10 and the two pioneer grass species on 9 and 10 out of 17 surveyed plots (Finkenbein et al., unpublished data). The species were chosen by their high frequency of occurrence since we expect this is an indication of the species' general adaptation to the conditions at the study site. The two exotic tree species (Acacia auriculiformis, Casuarina equisetifolia) chosen for analysis are currently planted in monocultures at the study site.

The description of all studied plant species and their surveyed natural occurrence at the study site are shown in Table 1. For simplicity, hereafter we will refer to the species by their genus name only.

\subsection{Experimental design and treatments}

The drought stress experiment was carried out in a greenhouse at the experimental station of the UFZ - Helmholtz Centre for Environmental Research in Bad Lauchstädt, Ger- 
Table 1. Description of studied plant species and their surveyed natural occurrence in post-mining areas in north-eastern Vietnam (occurrence data base on Finkenbein et al., unpublished data).

\begin{tabular}{llllll}
\hline Plant species & Family & Growth form & Leaf anatomy & Origin & Occurrence \\
\hline Acacia auriculiformis A. Cunn. ex Benth. & Fabaceae & Tree & Sclerophyllous & Exotic & Planted \\
Casuarina equisetifolia J. R. Forst. \& G. Forst. & Casuarinaceae & Tree & Sclerophyllous & Exotic & Planted \\
Commersonia bartramia (L.) Merr. & Malvaceae & Tree & Mesophyllous & Native & $6 / 17$ plots \\
Mallotus barbatus (Wall.) Müll. Arg. & Euphorbiaceae & Tree & Mesophyllous & Native & $4 / 17$ plots \\
Melia azedarach L. & Meliaceae & Tree & Mesophyllous & Native & $3 / 17$ plots \\
Rhus chinensis Mill. & Anacardiaceae & Tree & Mesophyllous & Native & $10 / 17$ plots \\
Saccharum spontaneum L. & Poaceae & Perennial grass & Sclerophyllous & Native & $10 / 17$ plots \\
Thysanolaena maxima (Roxb.) Kuntze & Poaceae & Perennial grass & Mesophyllous & Native & $9 / 17$ plots \\
\hline
\end{tabular}

many, in 2010. Seeds for each species were collected at the study site in Vietnam in 2009 according to their ripeness at different times of the year.

Since our aim was to study the species' response to drought stress under controlled conditions, our study did not claim to use a substrate chemically identical to those of the study site in Vietnam. Therefore, we germinated the collected seeds in a soil-sand mixture $(2: 3)$ and transplanted the same-aged tree saplings and juvenile grasses after 3 months to pots containing $5 \mathrm{dm}^{3}$ of a coarse-grained model substrate (9: 1 mixture of waste rock pile material and compost) with a low maximum water storage capacity of $25.5 \%$. The waste rock pile material originated from a hard coal mine near Oelsnitz/Erzgebirge, Germany. It was sieved to pass $25 \mathrm{~mm}$. The compost was provided by a composting facility in Teutschenthal, Germany.

One month after transplanting we started the experiment with two treatments of water supply. In the control treatment, the plants were watered three times a week. In the drought treatment, the plants were watered once a week to cause moderate drought stress. At each watering, the pots were weighed and filled with water to reach a gravimetric soil water content of $20.6 \%$.

The experiment was set up in a randomized block design: one individual of each species $x$ treatment combination was randomly placed on each of five greenhouse tables, which represented the blocks. Three additional individuals of each species and treatment were placed on the tables for destructive measurements and to replace dying plants before the start of the experiment. Every week, the pots were newly randomized within the five tables.

For comparative purposes we used standardized climatic conditions based on mean values with the aim of fitting the average conditions of the study site in Vietnam. Taking into account the technical constraints of a greenhouse in central Europe, these conditions were simulated as closely possible to those in Vietnam. We set a day: night cycle to $d: n=12 \mathrm{~h}: 12 \mathrm{~h}$ and $25^{\circ} \mathrm{C}: 18^{\circ} \mathrm{C}$ and adjusted the air humidity between $60 \%$ (day) and $80 \%$ (night). Temperature and humidity were measured by hygrothermographs (Hygro-Thermograph, Thies Clima, Göttingen, Germany).
Table 2. List of studied functional traits with abbreviations and units.

\begin{tabular}{lll}
\hline Abbreviation & Trait & Unit \\
\hline$B_{\mathrm{T}}$ & Total dry biomass & $\mathrm{g}$ \\
$B_{\mathrm{S}}$ & Shoot dry biomass & $\mathrm{g}$ \\
$B_{\mathrm{R}}$ & Root dry biomass & $\mathrm{g}$ \\
$\mathrm{RER}_{\max }$ & Maximum relative & per week \\
& elongation rate & \\
$R: S$ & Root : shoot ratio & - \\
SRL & Specific root length & $\mathrm{mg}^{-1}$ \\
RLD & Root length density & $\mathrm{m} \mathrm{dm}^{-3}$ \\
SLA & Specific leaf area & $\mathrm{cm}^{2} \mathrm{~g}^{-1}$ \\
LAR & Leaf area ratio & $\mathrm{m}^{2} \mathrm{~kg}^{-1}$ \\
LA : RL & Leaf area : root length ratio & $\mathrm{m}^{2} \mathrm{~km}^{-1}$ \\
$g_{\mathrm{s}}$ & Stomatal conductance & $\mathrm{mmol} \mathrm{m}^{-2} \mathrm{~s}^{-1}$ \\
$\psi_{\text {leaf }}$ & Water potential & $\mathrm{MPa}$ \\
\hline
\end{tabular}

With $400 \mathrm{~W}$ lamps, we achieved a light intensity (photosynthetically active photon flux density) between 150 and $300 \mu \mathrm{mol} \mathrm{m}^{-2} \mathrm{~s}^{-1}$.

\subsection{Measurements}

Over a period of 7 weeks, morphological and ecophysiological traits ("functional traits") related to drought resistance were measured or derived from the measured parameters (Table 2).

Functional traits were measured per individual plant at the final harvest, except for plant height, which was measured weekly. For the determination of plant height we measured the length of the trees' main shoot axis and the length of the grasses' longest leaf. Using these data we calculated maximum relative elongation rate $\left(\mathrm{RER}_{\max }\right)$ as the maximum slope of the regression line of the logarithmically transformed height data against time. Biomass was measured after drying at $60^{\circ} \mathrm{C}$ for $48 \mathrm{~h}$ separately for leaves, shoot axes, fine roots (absorptive organs for water and nutrients, $\varnothing \leq 0.5 \mathrm{~mm}$ ), and coarse roots (storage and anchoring organs, $\varnothing>0.5 \mathrm{~mm})$. Shoot biomass $\left(B_{\mathrm{S}}\right)$ and root biomass 
$\left(B_{\mathrm{R}}\right)$ were calculated as the sum of all aboveground and belowground parts of plants respectively. Total biomass $\left(B_{\mathrm{T}}\right)$ was calculated as the sum of $B_{\mathrm{S}}$ and $B_{\mathrm{R}}$. Root: shoot ratio $(R: S)$ was calculated as the ratio of $B_{\mathrm{R}}$ to $B_{\mathrm{S}}$.

We calculated specific root length (SRL) as the ratio of fine root length to fine root dry biomass, and root length density (RLD) as the ratio of total root length (sum of fine and coarse root length) to the volume of the root-permeated substrate $\left(5 \mathrm{dm}^{3}\right)$. For this purpose, we determined the root length of fine roots and coarse roots by analysing photographs of root subsamples with the software WinRHIZO ${ }^{\mathrm{TM}}$ (Regent Instruments, Montreal, Canada) and measured the dry biomass of these samples.

For the calculation of specific leaf area (SLA) as the ratio of leaf area to leaf dry biomass we determined the leaf area of leaf subsamples with an area meter (LI-3100, LI-COR Biosciences, Lincoln, USA) and measured the dry biomass of these samples. For Casuarina, we used photosynthetically active small twigs instead of leaves, and for Acacia we used photosynthetically active flattened petioles (phyllodes) to determine leaf area. For the calculation of leaf area ratio (LAR) as the ratio of total leaf area to $B_{\mathrm{T}}$, we calculated total leaf area by multiplying total leaf biomass and SLA. For the calculation of leaf area : root length ratio (LA:RL) as the ratio of total leaf area to total fine root length, we calculated total fine root length by multiplying total fine root biomass and SRL.

Stomatal conductance $\left(g_{\mathrm{s}}\right)$ was measured with a leaf porometer (SC-1, Decagon Devices Inc., Pullman, USA). To measure water potential $\left(\psi_{\text {leaf }}\right)$, we used a Scholander pressure chamber (SKPM 1400/80, Skye Instruments Ltd, Llandrindod Wells, UK). Due to the experimental design with the high number of individuals and species, the aim of measuring $g_{\mathrm{s}}$ and $\psi_{\text {leaf }}$ was to get information about differences between the species but not to analyse the responses of each species to varying climatic conditions and plant water status during a daily course in detail. To reduce systematical errors on the days of measurement, all recordings were randomized for species and treatment individuals during the course of a day, and daily means are shown in the graphs (Fig. 1k and 1).

Because of the destructive method for measuring $\psi_{\text {leaf }}$, we used the available additional individuals (two or three per species). For the determination of SLA, $g_{\mathrm{s}}$, and $\psi_{\text {leaf }}$ we used the youngest mature leaf of each individual plant for samples. For Casuarina $g_{\mathrm{s}}$ and $\psi_{\text {leaf }}$ could not be measured since leaves were too small. For reasons of time we determined fine and coarse root length only for three of the five experimental blocks, which were used for the calculation of SRL, RLD, and LA : RL. For Thysanolaena, $g_{\mathrm{s}}$, SRL, RLD, and LA : RL data of one individual were missing.

\subsection{Data analysis}

In order to look for significant differences on the performance of native and exotic species under drought, we per- formed ANOVAs ( $\mathrm{lm}$ function in stats package of R; R Development Core Team, 2011; $F$ test at $p \leq 0.05$ ) with block and origin as fixed factors. Block represents the five (except three for SRL, RLD, and LA : RL) experimental tables (replicates), and origin is the distinction of native and exotic species. We considered species nested in origin as a fixed factor, too, because the studied species were deliberately selected according to their high abundance on the post-mining areas rather than representing a random sample out of the species pool. Since differences between native grasses and trees were expected a priori, for each trait, we conducted two ANOVAs: one model contrasting native trees versus exotic trees, and one model contrasting native grasses versus exotic trees because our aim was to investigate the suitability of native species for restoration as an alternative to exotic species.

To approach normal distribution of residuals and homogeneity of variances, data of $B_{\mathrm{T}}, B_{\mathrm{S}}, B_{\mathrm{R}}, R: S$, SRL, RLD, SLA, LA:RL, $g_{\mathrm{s}}$, and $\psi_{\text {leaf }}$ were log-transformed and data of LAR were square-root-transformed prior to analyses. No transformation was needed for $\mathrm{RER}_{\max }$.

\section{Results}

The comparison of native trees and grasses each with exotic trees revealed differences in most of the functional traits and their response to drought (Fig. 1a-1; Table 3a and b).

Both native trees and native grasses had significantly higher $B_{\mathrm{T}}, B_{\mathrm{S}}$, and $B_{\mathrm{R}}$ than exotic trees. Under drought, $B_{\mathrm{T}}$ was reduced on average by $41 \%$ for native trees and by $35 \%$ for native grasses, whereas it was reduced by $21 \%$ for the exotic Acacia and even increased by $38 \%$ for the exotic $\mathrm{Ca}$ suarina. For RER $\mathrm{m}_{\max }$ both native groups did not significantly differ from exotic trees. Under drought, native trees had a higher reduction of $\mathrm{RER}_{\max }$ than exotic trees, whereas native grasses and exotic trees did not differ significantly in the reduction of $R R_{\max }$.

According to their higher $R: S$, native trees and native grasses invest more resources in root compared to shoot biomass than exotic trees. However, the comparison of native trees and exotic trees showed no significantly different response of $R: S$ to drought. In contrast, $R: S$ was significantly reduced for native grasses, whereas for exotic trees it was significantly increased under drought. Native trees displayed a significantly lower SRL than exotic trees, whereas SRL of native grasses was similar to SRL of exotic trees. For SRL, no significant drought response could be observed for any of the functional groups. Regarding RLD, both native groups, in particular native grasses, displayed significantly higher values than exotic trees. In response to drought, RLD was reduced for native trees, whereas for native grasses and exotic trees no difference in their response to drought could be observed. Rather, species' response to drought varied within both native grasses and exotic trees. 

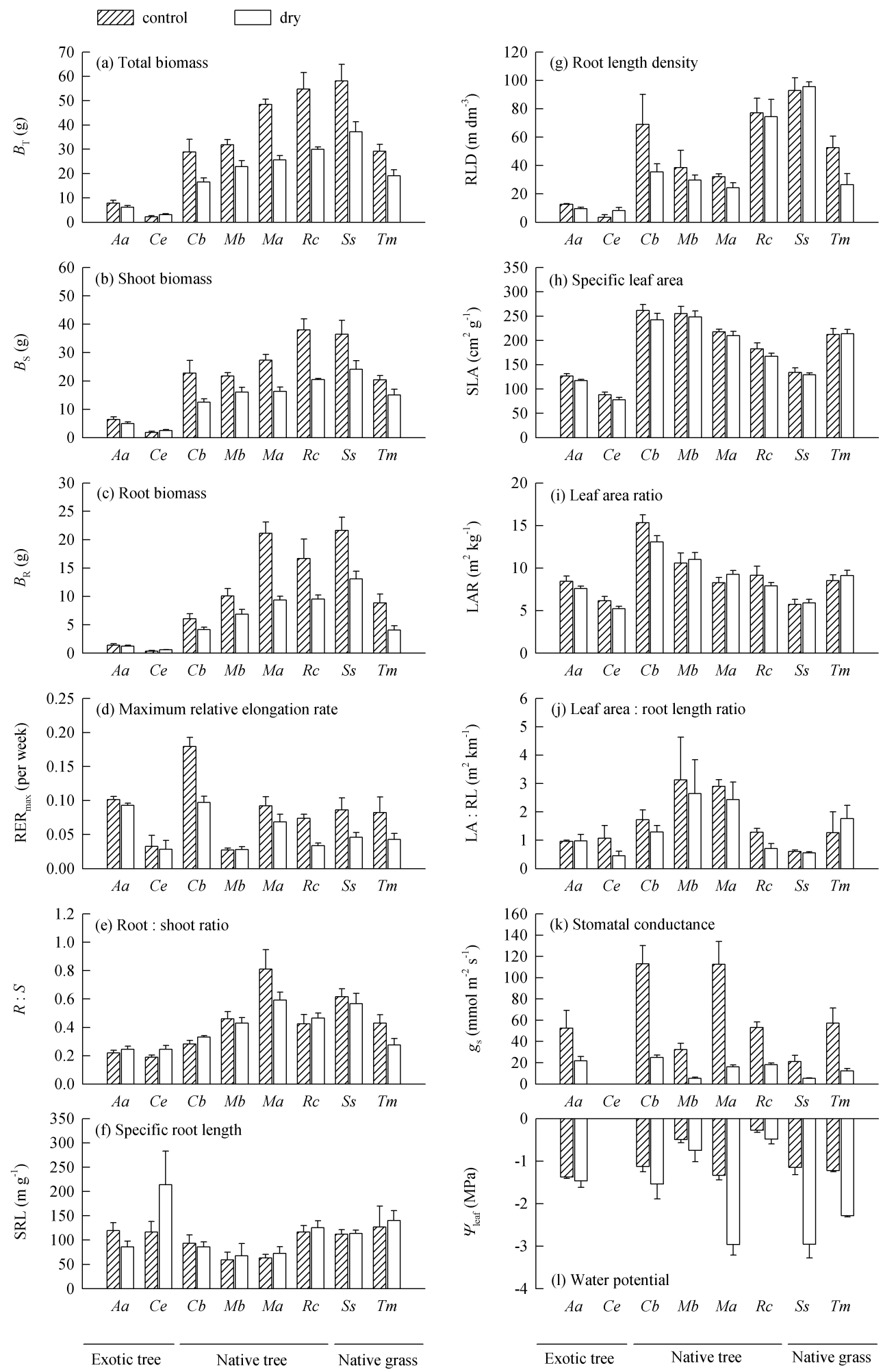

Figure 1. Functional traits related to drought resistance of two exotic tree species (Aa, Acacia auriculiformis; Ce, Casuarina equisetifolia), four native tree species ( $C b$, Commersonia bartramia; Mb, Mallotus barbatus; Ma, Melia azedarach; Rc, Rhus chinensis), and two native grass species (Ss, Saccharum spontaneum; Tm, Thysanolaena maxima) measured in a control and a dry treatment. All values are individual based means $( \pm$ SE). 


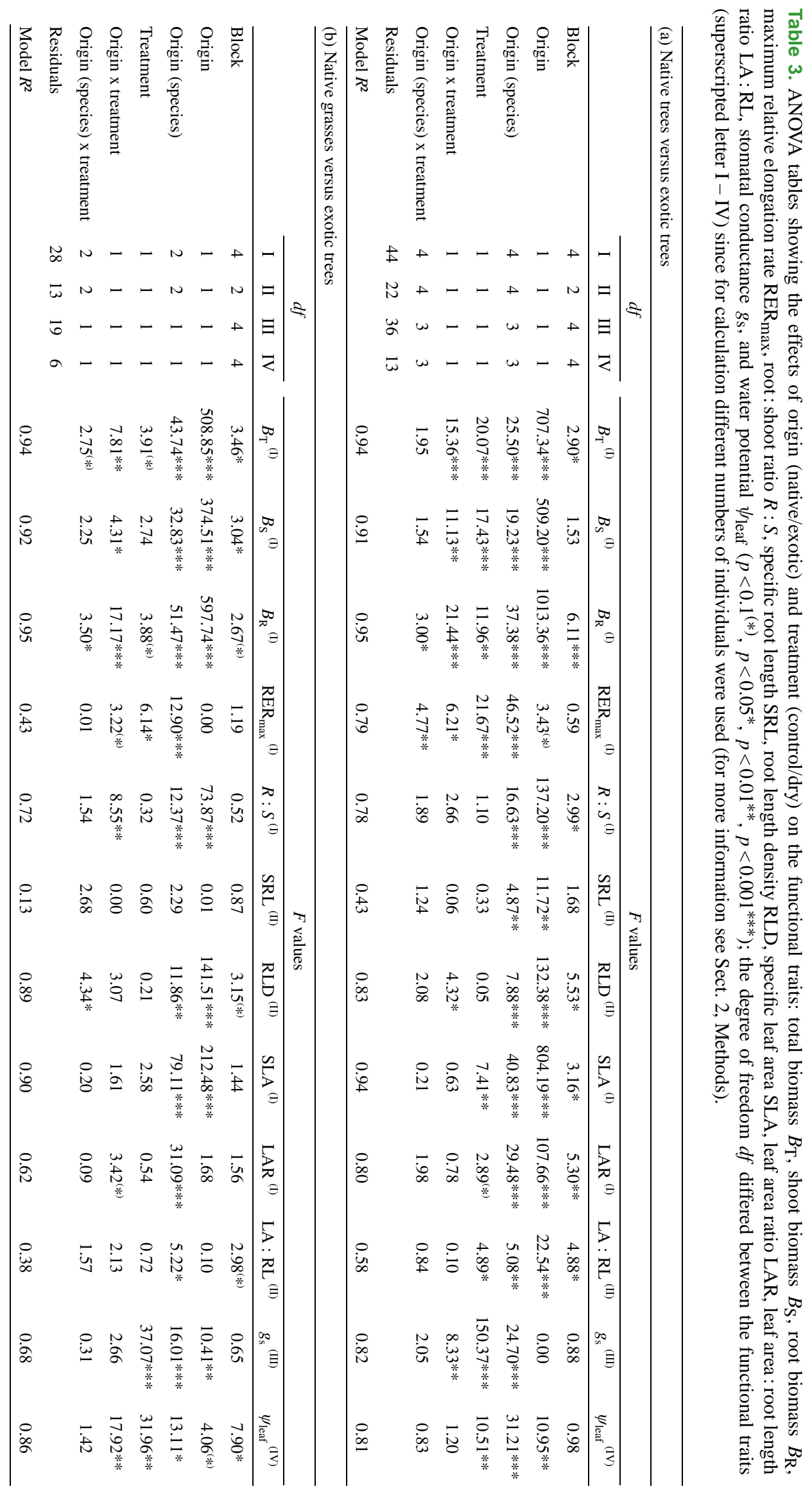


Concerning SLA, both native trees and native grasses showed significantly higher values than exotic trees. Moreover, native trees had significantly higher LAR and LA : RL than exotic trees. In contrast, native grasses did not differ from exotic trees concerning LAR and LA:RL. Under drought, SLA and LA:RL were significantly reduced for both native trees and exotic trees. However, in contrast to that, the comparison of native grasses and exotic trees did not reveal a significant response of SLA, LAR, and LA : RL to drought for any of these groups.

Stomatal conductance $\left(g_{\mathrm{s}}\right)$ varied highly within both native groups, especially within native trees. This might be the reason that for $g_{\mathrm{s}}$ no significant differences between native trees and the exotic tree Acacia could be verified. Native grasses had in general a lower $g_{\mathrm{s}}$ than Acacia. Under drought, $g_{\mathrm{s}}$ was reduced for each of the three groups. This reduction was significantly higher for native trees (from Rhus by $66 \%$ to Melia by $86 \%$ ) than for Acacia (by $58 \%$ ). For all groups, drought decreased $\psi_{\text {leaf }}$. This indicates that our drought treatment was severe enough to create drought stress. Particularly, native grasses responded to drought with a stronger decrease of $\psi_{\text {leaf }}$ than Acacia.

\section{Discussion}

\subsection{Drought resistance of native pioneer species in comparison to exotic species}

Overall, regarding drought resistance, the results of the comparison of functional traits and their response to drought indicate that the studied native trees and native grasses are a suitable alternative to the currently planted drought-resistant exotic tree species. However, native trees and native grasses differed positively or negatively in several traits from the exotic trees.

At first sight, a lower drought resistance of the native trees compared to exotic trees is indicated by the higher wholeplant indicator LA:RL, which represents the proportion of transpiring surface area (water demand) to absorbing surface (water supply) (Heilmeier et al., 2001; Rhodenbaugh and Pallardy, 1993), as well as by the higher leaf parameters SLA and LAR (Liu et al., 2011). But the similar drought-induced reduction of LA:RL and SLA of native and exotic trees, as a mechanism usually related to drought resistance (Costa e Silva et al., 2004), proved the plastic response of the native trees to drought.

Another piece of evidence of the native trees' acclimatization to drought is their ability to reduce $g_{\mathrm{s}}$ even more than the exotic Acacia trees as primary regulation of water balance. This means that both native and exotic trees tend to adjust water loss by stomatal closure, which was also reported by Brodribb and Holbrook (2003), rather than by reducing photosynthetically active leaf or phyllode area with respect to total biomass. For the native tree Melia the reduction of $g_{\mathrm{s}}$ has also been reported by Nautiyal et al. (1994): as a re- sponse to drought this species reduces the number and length of stomata per unit leaf area and the number and width of open stomata per unit leaf area significantly. We assume that the stronger drought-induced reduction of $g_{\mathrm{s}}$ in combination with the reduction of LA : RL and SLA of the native trees are responsible for their stronger drought-induced reduction of $\mathrm{RER}_{\max }$ and biomass.

The high $R: S$ of the native tree saplings can be seen as a major morphological adaptation to drought since a study with Mediterranean shrub species found a positive relation between biomass allocation to roots and seedling survival (Lloret et al., 1999). However, a shift of $R: S$ in favour of root during water deficit as a mechanism maintaining functional balance between root and shoot (Ericsson et al., 1996) could be verified neither for native trees nor for exotic trees.

The generally lower SRL (thicker roots) of the native trees, except for Rhus, compared to the exotic trees suggests a lower effectiveness of the water uptake system. However, thicker fine roots are able to penetrate soil more easily and anchor plants more effectively, which is particularly advantageous for the restoration of coarse-grained waste rock dumps. Moreover, through the greater diameter of the vascular bundle, thicker roots have a higher water (and nutrient) transport capacity than thinner roots (Hutchings and John, 2003). Therefore, and since the exotic trees also showed no significant response to drought for both $R: S$ and SRL, the native trees displayed a similar suitability to drought conditions to the exotic trees regarding these root parameters.

In combination with an RLD which was, despite a drought-induced reduction, still higher than for the exotic trees, the native trees can be characterized by a welldeveloped root system, mostly due to their high $R: S$.

For the native grasses, our hypothesis of a drought resistance comparable to the resistance of the exotic tree saplings was confirmed by their similar RER max $_{\text {ax }}$ and by their similar drought-induced reduction of $\mathrm{RER}_{\max }$ and $g_{\mathrm{s}}$. In addition, their SRL, SLA, LAR, and LA : RL did not change significantly under drought, similar to the exotic trees.

The stronger decrease in $\psi_{\text {leaf }}$ of the native grasses may be related to their high SLA and indicates drought stress. Nevertheless, the ability to reduce $g_{\mathrm{s}}$ under drought similar to the exotic Acacia and the rolling of leaves observed for both grass species, a mechanism to avoid water loss (O'Toole and Chang, 1978), indicate the acclimatization of the grass leaves to drought.

Still, low $g_{\mathrm{s}}$ also entails low $\mathrm{CO}_{2}$ uptake available for photosynthesis, which seems to explain the stronger reduction of biomass under drought. However, a reason for the still considerably high biomass of our studied native grasses, even under drought, might be their high water-use efficiency. Cernusak et al. (2007) found that the $\mathrm{C}_{4}$ grass Saccharum had the highest water-use efficiency in comparison to seven $\mathrm{C}_{3}$ tree species, and, in spite of being a $\mathrm{C}_{3}$ plant, Thysanolaena showed a water-use efficiency within the value range of $\mathrm{C}_{4}$ plants (Bhuchar, 2001; Lambers et al., 2008). Therefore, and 
due to their well-developed root system, illustrated by their RLD being significantly higher than for exotic trees, the studied native grasses are well adapted to arid-hot climates.

\subsection{Use of native pioneer species for the restoration of post-mining areas}

Although exotic monocultures may provide an economically and technically attractive solution for a fast restoration of post-mining areas, an ecological restoration using mixtures of native species is expected to provide higher benefits regarding ecosystem services and biodiversity, and a higher resistance to various environmental stresses (Benayas et al., 2009; McNamara et al., 2006). Drought is a stress factor highly important to plants growing in post-mining areas because, due to the high surface run-off on the steep slopes and the low water storage capacity of the coarse-grained substrate, water availability during dry season is limited. Our study showed that native pioneer species are resistant to moderate drought stress.

Moreover, through their well-developed root system they are well suited for soil stabilization. Other studies have already recommended the studied perennial grasses Thysanolaena and Saccharum for planting in hedgerows to stabilize steep landslide-prone slopes or to reduce soil erosion in agriculture (Khisa et al., 2004; Sharma, 2004). Thysanolaena can also tolerate high lead concentrations in soil and accumulates lead mostly in roots. Therefore, it is well suited for phytostabilization in mining areas with high lead concentrations (Rotkittikhun et al., 2007).

For these reasons we consider native grasses as an important component of soil bioengineering restoration of postmining areas, but not as a pioneer vegetation for following forests, since due to the high competitiveness of perennial grasses such as Saccharum spontaneum they also have the potential to hamper further succession (Hammond, 1999). However, on the landscape scale, they increase biodiversity.

Furthermore, as shown in our study, the native pioneer species are characterized by a considerably high biomass production, even under drought, which facilitates the development of a dense vegetation cover in a short time. In addition, the high SLA of the native pioneer species indicates a fast decomposability of their leaf litter, which has a positive influence on soil formation (Santiago, 2010) and reduces fire hazard. Overall, the responses of functional traits of native trees and grasses studied in this experiment make them promising species for an ecological restoration of postmining areas in Vietnam.

Ecologically restored post-mining areas have a potential for long-term regeneration of forest and biodiversity as these marginal areas usually do not compete with agricultural crop cultivation. This is important since biodiversity is endangered in Vietnam as species-rich and closed-canopy forests constitute only $4.6 \%$ (in 2004) of total natural forests (Socialist Republic of Vietnam \& UN-REDD Programme,
2009). Still, the awareness of the importance of ecological restoration in Vietnam seems to be increasing as the Forest Science Institute of Vietnam (FSIV) has evaluated native tree species of later successional stages for reforestation (Sam and Nghia, 2002). In this context, our study showed that there are drought-resistant native pioneer species, which might be used to accelerate secondary succession by facilitating the establishment of such targeted higher-value native species of later successional stages. Nevertheless, although we are aware of the need for further studies on other adverse environmental factors such as nutrient limitation or toxic chemicals, our results indicate the potential suitability of native pioneer species for restoration of post-mining areas.

Acknowledgements. We thank the team of the experimental station in Bad Lauchstädt for assistance with the implementation and the harvest of the experiment. Furthermore, we thank Dr. Sonja Knapp for helpful comments and suggestions on the manuscript.

This work was framed within the project RAME - Research Association Mining and Environment (02WB0957) - and funded by the German Ministry for Education and Research (BMBF). The responsibility for the contents of this contribution lies with the authors.

Edited by: D. Montesinos

Reviewed by: two anonymous referees

\section{References}

Benayas, J. M. R., Newton, A. C., Diaz, A., and Bullock, J. M.: Enhancement of biodiversity and ecosystem services by ecological restoration: A meta-analysis, Science, 325, 1121-1124, 2009.

Bhuchar, S. K.: An eco-physiological evaluation of Thysanolaena maxima (Broom grass): A multipurpose, perennial grass of high fodder value, Ph.D. thesis, Kumaun University, Nainital, India, 2001.

Brodribb, T. J. and Holbrook, N. M.: Stomatal closure during leaf dehydration, correlation with other leaf physiological traits, Plant Physiol., 132, 2166-2173, 2003.

Bui, X. N. and Nguyen, P. V.: Surface coal mining in Quang Ninh and environmental problems need caring, in: International workshop 25-27 October 2007: Geoecology and Environmental Technology, edited by: Bui, H., Werner, P., Dang, K. C., Tsuji, K., Dinh, T. H., Le, H. A., and Bui X. N., Labour Publishing House, Hanoi, Vietnam, 224-234, 2007.

Castro, J., Zamora, R., and Hódar, J. A.: Restoring Quercus pyrenaica forests using pioneer shrubs as nurse plants, Appl. Veg. Sci., 9, 137-142, 2006.

Cernusak, L. A., Aranda, J., Marshall, J. D., and Winter, K.: Large variation in whole-plant water-use efficiency among tropical tree species, New Phytol., 173, 294-305, 2007.

Condit, R., Hubbell, S. P., and Foster, R. B.: Mortality rates of 205 neotropical tree and shrub species and the impact of a severe drought, Ecol. Monogr., 65, 419-439, 1995.

Costa e Silva, F., Shvaleva, A., Maroco, J. P., Almeida, M. H., Chaves, M. M., and Pereira, J. S.: Responses to water stress in 
two Eucalyptus globulus clones differing in drought tolerance, Tree Physiol., 24, 1165-1172, 2004.

Ekka, N. J. and Behera, N.: Species composition and diversity of vegetation developing on an age series of coal mine spoil in an open cast coal field in Orissa, India, Tropical Ecology, 52, 337343, 2011.

Engelbrecht, B. M. J., Dalling, J. W., Pearson, T. R. H., Wolf, R. L., Gálvez, D. A., Koehler, T., Tyree, M. T., and Kursar, T. A.: Short dry spells in the wet season increase mortality of tropical pioneer seedlings, Oecologia, 148, 258-269, 2006.

Ericsson, T., Rytter, L., and Vapaavuori, E.: Physiology of carbon allocation in trees, Biomass Bioenerg., 11, 115-127, 1996.

Goosem, S. P. and Tucker, N. I. J.: Repairing the rainforest - theory and practice of rainforest re-establishment in North Queensland's wet tropics, WetTropics Management Authority, Cairns, Australia, 21-41, 1995.

Hammond, B. W.: Saccharum spontaneum (Gramineae) in Panama, J. Sustain. For., 8, 23-38, 1999.

Hata, K., Kato, H., and Kachi, N.: Litter of an alien tree, Casuarina equisetifolia, inhibits seed germination and initial growth of a native tree on the Ogasawara Islands (subtropical oceanic islands), J. Forest Res.-Jpn., 15, 384-390, 2010.

Hau, B. C. H. and Corlett, R. T.: Factors affecting the early survival and growth of native tree seedlings planted on a degraded hillside grassland in Hong Kong, China, Restor. Ecol., 11, 483-488, 2003.

Heilmeier, H., Erhard, M., Wartinger, A., Brinckmann, E., Horn, R., and Schulze, E. D.: Biomass partitioning in response to soil drought: A pot experiment with Prunus dulcis trees during four years, Basic Appl. Ecol., 2, 165-175, 2001.

Hutchings, M. J. and John, E. A.: Distribution of roots in soil, and root foraging activity, in: Root Ecology, edited by: de Kroon, H. and Visser, E. J. W., Springer-Verlag Berlin Heidelberg New York, Heidelberg, Germany, 33-60, 2003.

Jones, C. G., Lawton, J. H., and Shachak, M.: Organisms as ecosystem engineers, Oikos, 69, 373-386, 1994.

Khisa, S. K., Alam, M. K., and Siddiqi, N. A.: Broom grass (Thysanolaena maxima) hedges: A bioengineering device for erosion control and slope stabilization, in: Ground and water bioengineering for erosion control and slope stabilization, edited by: Barker, D. H., Watson, A. J., Sombatpanit, S., Northcutt, B., and Maglinao, A. R., Science Publishers, Inc., Enfield, USA, 143 149,2004

Lamb, D.: Large-scale ecological restoration of degraded tropical forest lands: The potential role of timber plantations, Restor. Ecol., 6, 271-279, 1998.

Lambers, H., Chapin III, F. S., and Pons, T. L.: Plant physiological ecology, 2nd Edn., Springer-Verlag, New York, USA, 206-207, 2008.

Liu, C. C., Liu, Y. G., Guo, K., Li, G. Q., Zheng, Y. R., Yu, L. F., and Yang, R.: Comparative ecophysiological responses to drought of two shrub and four tree species from karst habitats of southwestern China, Trees-Struct. Funct., 25, 537-549, 2011.

Lloret, F., Casanovas, C., and Peñuelas, J.: Seedling survival of Mediterranean shrubland species in relation to root:shoot ratio, seed size and water and nitrogen use, Funct. Ecol., 13, 210-216, 1999.

Markesteijn, L., Poorter, L., Paz, H., Sack, L., and Bongers, F.: Ecological differentiation in xylem cavitation resistance is associated with stem and leaf structural traits, Plant Cell Environ., 34, 137148, 2011.

McNamara, S., Tinh, D. V., Erskine, P. D., Lamb, D., Yates, D., and Brown, S.: Rehabilitating degraded forest land in central Vietnam with mixed native species plantings, Forest Ecol. Manag., 233, 358-365, 2006.

Morris, T. L., Esler, K. J., Barger, N. N., Jacobs, S. M., and Cramer, M. D.: Ecophysiological traits associated with the competitive ability of invasive Australian acacias, Divers. Distrib., 17, 898910, 2011.

Nautiyal, S., Badola, H. K., Pal, M., and Negi, D. S.: Plant responses to water stress: changes in growth, dry matter production, stomatal frequency and leaf anatomy, Biol. Plantarum, 36, 91-97, 1994.

O'Toole, J. C. and Chang, T. T.: Drought and rice improvement in perspective, IRRI Research Paper Series, No. 14, International Rice Research Institute, Manila, Philippines, 1978.

Poorter, L. and Hayashida-Oliver, Y.: Effects of seasonal drought on gap and understorey seedlings in a Bolivian moist forest, J. Trop. Ecol., 16, 481-498, 2000.

R Development Core Team: R: A language and environment for statistical computing, R Foundation for Statistical Computing, Vienna, Austria, 2011.

Rhodenbaugh, E. J. and Pallardy, S. G.: Water stress, photosynthesis and early growth patterns of cuttings of three Populus clones, Tree Physiol., 13, 213-226, 1993.

Richardson, D. M.: Forestry trees as invasive aliens, Conserv. Biol., 12, 18-26, 1998.

Richardson, D. M. and Rejmánek, M.: Trees and shrubs as invasive alien species - a global review, Divers. Distrib., 17, 788-809, 2011.

Rotkittikhun, P., Chaiyarat, R., Kruatrachue, M., Pokethitiyook, P., and Baker, A. J. M.: Growth and lead accumulation by the grasses Vetiveria zizanioides and Thysanolaena maxima in leadcontaminated soil amended with pig manure and fertilizer: A glasshouse study, Chemosphere, 66, 45-53, 2007.

Saharjo, B. H. and Watanabe, H.: Estimation of litter fall and seed production of Acacia mangium in a forest plantation in South Sumatra, Indonesia, Forest Ecol. Manag., 130, 265-268, 2000.

Sam, D. D. and Nghia, N. H.: Use of indigenous tree species in reforestation in Vietnam, Forest Science Institute of Vietnam and Japan International Cooperation Agency, Agricultural Publishing House, Hanoi, Vietnam, 1-93, 2002.

Santiago, L. S.: Can growth form classification predict litter nutrient dynamics and decomposition rates in lowland wet forest? Biotropica, 42, 72-79, 2010.

Sharma, C.: Indigenous soil erosion control and slope stabilization techniques in the hills and mountains of Nepal, in: Ground and water bioengineering for erosion control and slope stabilization, edited by: Barker, D. H., Watson, A. J., Sombatpanit, S., Northcutt, B., and Maglinao, A. R., Science Publishers, Inc., Enfield, USA, 207-215, 2004.

Socialist Republic of Vietnam \& UN-REDD Programme: Revised Standard Joint Programme Document, URL: http://www.fao.org/fileadmin/user_upload/faovn/docs/Viet_ Nam_UNREDD_JPD_Final.pdf (last access: 4 August 2012), 2009. 
Thu, V.: Oceanographic and meteorological characterisation of the Ha Long Bay, Station for Climate, Marine Hydrology and Environment Bãi Cháy, Ha Long, Vietnam, 2000.

Turner, I. M.: The seedling survivorship and growth of three Shorea species in a Malaysian tropical rain forest, J. Trop. Ecol., 6, 469478, 1990.

US Energy Information Administration: International energy outlook 2011, Report DOE/EIA-0484, US Department of Energy, Washington, DC, USA, 2011.
Veenendaal, E. M., Ernst, W. H. O., and Modise, G. S.: Effect of seasonal rainfall pattern on seedling emergence and establishment of grasses in a savanna in south-eastern Botswana, J. Arid Environ., 32, 305-317, 1996.

Vitousek, P. M., D’Antonio, C. M., Loope, L. L., Rejmánek, M., and Westbrooks, R.: Introduced species: A significant component of human-caused global change, New Zeal. J. Ecol., 21, 1-16, 1997. 